\title{
Exploring the Cultural Regeneration Mechanism of the Rise of Western Powers on the Anthropological Level
}

\author{
Weizhang Jia, Shufang Zhang \\ Zhejiang Yuexiu University, Shaoxing, China \\ Email: 20131050@zyufl.edu.cn
}

How to cite this paper: Jia, W.Z. and Zhang, S.F. (2021) Exploring the Cultural Regeneration Mechanism of the Rise of Western Powers on the Anthropological Level. Open Access Library Journal, 8: e7756.

https://doi.org/10.4236/oalib.1107756

Received: July 13, 2021

Accepted: September 25, 2021

Published: September 28, 2021

Copyright $\odot 2021$ by author(s) and Open Access Library Inc.

This work is licensed under the Creative Commons Attribution International License (CC BY 4.0).

http://creativecommons.org/licenses/by/4.0/

\begin{abstract}
This paper explores the cultural regeneration mechanism of the rise of western powers from the anthropological level. The culture of major western countries is based on western civilization. Western civilization firstly embodied the democratic spirit of ancient Greek and Roman culture, and was deeply influenced by the spread of Christianity and Christian culture, which has played a decisive role in the rise of major western powers later. In this process, from the anthropological level, the model of Viking culture, or the Norse barbarian culture model, is the model of the development of western powers. However, each part of the Viking cultural model of exploration, plundering, warriors, trade and colonization, was permeated with the spread and influence of Christian culture. Therefore, it can be said that the cultural regeneration mechanism of western powers is the coupling of Viking culture model and Christian culture, which has also undergone the evolution of different historical stages, and both are indispensable.
\end{abstract}

\section{Subject Areas}

Anthropology, Culture

\section{Keywords}

Anthropology, Western Powers, Cultural Regeneration Mechanism, Viking Culture Model, Christianity

\section{1. 引言}

谈及西方文明的起源, 两方面事实已经被公认。一是从地域上, 西方文 
明的发源起始于中东两河流域、通过月形沃湾 ${ }^{1}$, 往返于尼罗河古埃及文明, 然后在南欧沿地中海地区形成古希腊、古罗马文明; 随着西罗马帝国的衰落, 法国、英国等民族国家兴起; 之后，随着德国的崛起，俄罗斯等中北欧国家 形成。二是从人种上看, 典型的最早的欧洲人应该是古希腊人、古罗马人, 而非日耳曼等北方 “蛮族”。但自公元 1500 年以后, 具有全球投射力的九个 西方大国依次崛起，分别是：意大利、葡萄牙、西班牙、荷兰、英国、法国、 德国、俄罗斯和美国。这些不断崛起的大国, 除意大利还有传统的拉丁民族 外, 其它大国则早就不再是罗马人的后裔了。

因此，西方大国文化的再生机制从人种上看是 “蛮族” 而非古希腊古罗 马人。“从西方大国文化再生机制的共性来看, 维京文化实体是西方大国原 型的共同初始值” 2 [1]。在人类早期迁徙过程中, 维京文化实体是以强迫扩 散为主、以战争方式直接移民为主要表征, 以外来的动态文化为主导、以本 土守成的农耕文化为主体嫁接而再生的新文化实体。再生的维京文化实体, 属于日耳曼文化圈, 在当时强势罗马文化视野中属于 “蛮族” 文化丛。类似 于我们通常提到的 “化外之地”。

该理论的提出, 在人类学层面上为探讨西方大国的文化本源以及发展演 化趋势提供了强有力的理论支撑。

\section{2. 西方文明与西方文化}

研究西方大国的文化机制, 必须依托西方文明。所以, 应该首先分清两 个概念: 文明与文化。在一个轮廓通常比较模糊的地理空间内, 文明的定义 就是指 “在一定社会范围内, 人们所见到的政治、社会、经济、宗教现象的 总体” ${ }^{3}$ [2]。而文化则属于一个更为主观的范畴。传统的定义认为, 文化的 概念是指 “人为了通过艺术、文学和科学来丰富自己的精神和情趣, 所需获 得的知识的总体。获得这些知识主要依靠教育和传播媒体” ${ }^{4}$ [2]。因此, 文 明较文化更客观一些, 文明是文化传播的基础。

谈及西方文明, 其核心内容无疑是从古希腊罗马流传下来的民主精神。 这种精神建立在一种信念的基础上, 即集体幸福来自于每个公民积极参与城 邦生活。从古希腊雅典城邦地方官的选举与轮流执政, 到梭伦改革后扩大参 政群体, 为后来民主精神的普及推广起了积极的推动作用。在古罗马时代, 这种民主精神又演变成了以元老院为首的管理模式。虽然这种精神在古希腊、 古罗马只适用于部分人群，并且之后不断人为地遭到破坏，但其精髓没有消 失，反而被继承下来，之后欧洲各国的议会制度的模式就是这一精神的展示。

在宗教方面, 西方文明的另一核心无疑就是基督教。基督教自创立后, 便受到了罗马帝国的逼迫和打压, 其原因是基督教与罗马帝国的多神传统宗 教相冲突。但基督教却凭借着其强大的生命力, 逐一消灭了罗马帝国的各个 1月形沃湾: 也称为 “新月沃土” 或 “肥胜月湾” (Fertile Cresent)是指中东两河流域及附近一连 串肥沃的土地, 位于今日的以色列、巴勒斯坦、黎巴濑、约旦、叙利亚, 以及伊拉克和土耳其 的东南部、埃及东北部。由于在地图上好像一弯新月, 所以美国芝加哥大学的考古学家詹姆士. 布 雷斯特德(James Henry Breasted)把这一大片肥美的土地称为 “新月沃土”。

${ }^{2}$ (汤正翔, 6 页)。

${ }^{3}$ (Aldebert, 9 页)。

${ }^{4}$ (Aldebert, 9 页)。 
神祇, 公元 380 年罗马帝国皇帝宣布基督教为罗马国教, 至此基督教成为罗 马帝国自身管理及外部教化的重要工具。基督教在把人与上帝联系起来时, 在宣布 “耶稣、上帝创造人类” 时, 给每个人的命运带来了个人的价值。灵 魂得救是基督徒的最大幸福。但这不是集体的事情, 而在于个人态度。基督 教精神反对把个人的成功与出身、财产、等级或荣誉联系起来, 承认问心无 愧地追求幸福。在这一点上, 基督教精神与古希腊流传下来的民主精神相契 合, 成为人道主义以及后来的人文主义的重要元素。重视人本身的才能, 在 上帝面前人人平等成为一种普世理念, 树立了一种新的理想。至此, 在罗马 帝国后期, 以基督教文化为主要特征的欧洲文化进入了一个全新的阶段, 神 权至高无上, 欧洲人就是按照这种理想造就的, 西方文明以及西方文化都以 此为核心。

既然文化区别于文明的最大之处在于知识的教育与传播, 那么我们就不 难看出西方文化主要因地域、民族等不同而不同。自公元 5 世纪罗马帝国解 体后, 欧洲大陆主要呈现出三大文化领域。东南部主要东罗马帝国及其后来 的拜占庭文化, 之后该地又经历了伊斯兰教的影响; 东部是斯拉夫领域, 受 亚洲、拜占庭、伊斯兰教和西部的影响; 西部文化领域把北欧和盘格鲁 - 萨 克逊文化与希腊、罗马遗产密切结合。这三大领域文化经常互相渗透。因此 这也为探讨西方文化的相似性提供了可能性。

公元八世纪后期, 在罗马文化、基督教文化和欧亚众多 “蛮族” 移民文 化构成的依附共生与缠绕制衡的欧洲地缘文化生态中，作为 “蛮族” 移民的 一类, 维京(Viking)文化实体投入到欧洲基督教世界, 成为此后欧洲地缘文化 生态渐变与突变的初始值, 与原有初始值一一基督教一起, 引领了欧洲/西方 文明的演化方向。至此, 我们可以看出西方文明有两大核心因素: 民主精神 与基督教精神。在两大精神的引导下, 各 “蛮族” 迅速适应当时的主流文化, 因时因地调整自己的生存方式, 逐渐被演化成当今西方大国的主流民族。不 可否认, 单凭希腊人、罗马人不可能完成欧洲或西方大国崛起的基业。在西 方大国崛起的过程中, 维京文化模式与基督教的教化作用无可替代、无可复 制。

当然, 我们应该明白维京文化实体中的维京人并非单指狭义上的维京海 盗。维京人(在人种上是被欧洲各地和各种语言称为诺曼人、北方人、瓦良格 人或罗斯人的民族), 身型高大, 在前维京时代信奉主神为奥丁的多神教、有 口头语言而无文字。构成维京再生移民文化的部族主要有： “伦巴第、苏维 汇、弗里西、朱特、法兰克、匈奴、阿瓦尔、斯拉夫、保加尔、阿兰、哥特、 汪达尔、盖格鲁和撒克逊” ${ }^{5}[1]$ 。以此, 我们可以看出, 维京人所涉及到的 “蛮族” 正是后来众多西方大国的民族主体。但这些 “蛮族” , 从一开始的 探险、劫掠, 逐渐被罗马文化和基督教文化所同化, 成为了文明的欧洲人。

公元 500 年, 适逢东罗马皇帝阿纳斯塔修斯在位。他还自以为是地认为 治下的罗马帝国东西统一、疆域广阔。但却不知此时的意大利总督是迪奥多 里克大帝, 是罗马人曾经恐惧万分的汪达尔人; 他也不曾想到勃艮第人贡德 波治理了阿尔卑斯山以北的区域、西哥特人亚拉里克二世治理了西班牙、法 5 (汤正翔, 234 页)。 
兰克人克洛维治理了高卢。此时的罗马帝国已经名存实亡, 众多 “蛮族” 已 经接管了欧洲的大部分地区，为之后欧洲民族国家的兴起奠定了基础。

\section{3. 基督教传播及基督教文化对西方大国的影响}

\section{1）基督教的诞生}

基督教起源于古希伯来人的犹太教。虽然基督教和犹太教同出一神宗教, 且教义密切关联, 但基督教无论从本身教义的扩展还是从受众面的扩大却远 远超越了犹太教。

在教义上，虽然耶稣在世传道不曾诋毁摩西的律法和先知的预言，但却 “数次宣称他来的使命是要成全律法” ${ }^{6}$ [3]。“耶稣和他的门徒都当众违反 犹太教的守安息日戒律” ${ }^{7}$ [3] [4], 并且耶稣对他的门徒说, “他是基督, 是 神的儿子” 8 [5]。他的到来是使万民得救。

在受众面上, 基督教认为, 不论什么民族, 凡敬畏神行义的人都为神所 悦纳, 所以基督教在传播过程中, 既面向犹太教教徒, 也向非犹太教教徒的 外邦人传递福音。而 “犹太教是一种民族性的宗教, 是犹太这个民族所特有 的宗教” ${ }^{9}[6]$ 。

基督教可就不同。它不是一个民族性的宗教, 不是哪一个民族所特有的 宗教。由此可见, 基督教从本质上是非民族的而普遍的一神教。当然, 基督 教的这种特征在创立初期, 受到了犹太教及罗马传统宗教的逼迫。在当时的 世界里, 基督教处于一种非常不利的地位。基督教教会成立以后, 围绕基督 徒是否按照犹太教戒律实施割礼的问题, 在耶路撒冷召开的教会决议予以了 明确的指示。“它冲破了犹太民族的狭险界限。它折断了犹太教束缚人的枷 锁。使那奉耶稣名的信仰有可能成为任何一个民族的信仰。如果这个信仰一 旦发展为宗教时, 它有可能成为具有世界意义的宗教” ${ }^{10}[6]$ 。

\section{2) 古希腊哲学思想与基督教神学的发展}

既然西方文明源于希腊文明, 那么古希腊哲学思想对以后基督教神学的 传播起促进作用就不足为奇了。苏格拉底在哲学上追求真正的善。苏格拉底 极力让人明白, 人所具有的那点灵魂同神的智慧是无法比拟的, 所以人当 “自 知无知” [7]。他相信神无处不在、无所不能, 万事万物都是神有意识有目的 的巧妙安排。作为苏格拉底的学生, 柏拉图认为宇宙开头是没有区别的一片 混沌。这片混沌的开辟是一个超自然的神的活动的结果。依照柏拉图的说法, 宇宙由混沌变得秩序井然, 其最重要的特征就是造物主为世界制定了一个理 性方案。之后的新柏拉图主义更是紧密地与基督教神学结合起来。新柏拉图 主义认为, 世界有两级, 一端是被称为 “上帝” 的神圣之光, 另一端则是完 全的黑暗。光与黑暗对应基督教的善与恶。

12 世纪末期, 随着亚里士多德的著作被人们所翻译, 人们逐渐认识到人 的知识来源于人的感觉。世界上不存在超自然的神, 人们不借助神的创造,

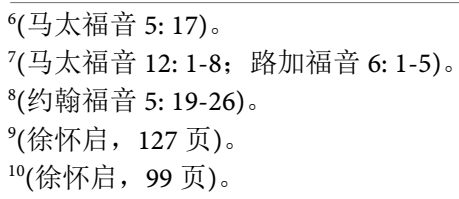


凭感觉和推理就可以理解知识。面对基督教信仰的动摇, 托马斯 - 阿奎那力 求捍卫人的理性与神的救赎的统一性。他认为, 如果运用恰当, 亚里士多德 的体验哲学可以推导出正确的结论, 但人的理性如果不借助于神的启示不可 能解决一切问题 ${ }^{11}[8]$ 。诸如神的本质、世界的创造、人的灵魂等问题必须借 助于神的启示才能得到答案。至此, 将基督教神学与亚里士多德的哲学相结 合的经院哲学诞生了。

文艺复兴以后, 随着人对自己本身能力的觉醒, 人们迫切要求思想的解 放。人们对教廷在政治思想上的束缚日益感到不满, 马丁 - 路德领导的宗教 改革应运而生。路德的信义宗主要涉及三方面的内容：公义来自于对上帝的 信心(惟信称义)、信心来自于神的话(惟圣经)、义人在上帝面前平等。随着新 教改革的深入进行, 欧洲各国逐渐摆脱了对罗马天主教的依赖。同时, 罗马 天主教内部也在进行着内部的自我改革, 以适应当时的社会发展。

由此可以看出, 基督教自诞生之日起, 就不断地与西方文明原有的因素 相契合, 逐渐适应发展中的变化, 代替其它因素, 在一次次嬗变中完善自我, 最终成为西方文明的内核因素。

“维京扩张者与基督教会互相依附共生” ${ }^{12}$ [1]。维京首领带领武士扩张 到欧洲各地，均不约而同地放弃自身多神教而有条件地的依基督教并强令部 属和属地居民也㤆依基督教。其中, 维京多数首领接受当地天主教, 如英格 兰、法兰西和从法兰西到意大利半岛建立西西里王国的维京雇佣军; 基辅罗 斯大公则接受临近拜占庭帝国东正教。维京扩张者与基督教会互相依附, 各 取所需。后世维京变异体均继承基督教传统, 从而使基督教成为维系社会秩 序和统治秩序最基本的价值观和最基本的社会规范。

\section{4. 西方大国原型的萌发与发展}

\section{1）西方大国的萌发}

公元五世纪是欧洲历史上不平凡的一段时期。在此期间, 罗马帝国面临 东西分裂, 西罗马帝国屡遭 “蛮族” 入侵。造成这一变化的根本原因是民族 大迁徙。而 “匈人成为了欧洲民族大迁徙和西罗马帝国灭亡的动力” ${ }^{13}$ [9]。 匈奴人来源于中国北方民族, 自中国秦朝起, 不断骚扰中国北方边境。后被 中国汉朝军队击败, 向西溃退, 进入欧洲。匈奴民族擅长骑射术, 彪悍勇猛, 生存能力强。公元四世纪, 匈奴人在欧洲立稳脚足后, 不断往西侵犯。先后 打败阿兰人、哥特人。这些战败民族的溃逃西进又造成了盖格鲁 - 萨克逊等 日耳曼民族的南侵与西进。西罗马帝国的衰落在很大程度上归因于外来 “蛮 族” 的入侵, 而罗马军队从不列颠的撤退, 为盎格鲁 - 萨克逊入侵不列颠提 供了可乘之机。虽然凯撒率领的罗马大军早在公元初就占领了不列颠, 但现 代英国的倠形要从公元五世纪的盎格鲁 - 萨克逊入侵算起。罗马对英国的影 响主要从公元 596 年坎特伯雷的传教士圣奥古斯丁说起。“奥古斯丁这批人 到了肯特王国之后，他们的热诚宣讲和圣洁的生活对国王和广大群众产生极 
大影响。597 年的五旬节时, 国王自己和数千个群众同时受洗入教。此后不 到五十年, 在肯特国王的影响下都相继接受基督教的信仰, 成为基督教的国 家” ${ }^{14}$ [6]。奥古斯丁为不列颠带来了基督教, 基督教对教化盎格鲁 - 萨克逊 等 “蛮族” 起了不可估量的作用。

公元六世纪早期, 东哥特人迪奥多里克大帝建立了意大利王国, 但之后 在另一 “蛮族” 伦巴第人的侵袭下, 政权沦落。其实际管理权落在了教廷身 上, 教皇格列高列成为当时人们所依赖的宗教与世俗领袖。

公元六世纪末溃败于高卢罗马人的西哥特人抵达西班牙, 借助于罗马法 律和管理模式建立政权。公元 711 年, 被伊斯兰教的穆斯林侵占, 成为穆斯 林国家。但到了 14 世纪, 在基督教文化的强势影响下, 异教徒政权迅速瓦解, 穆斯林徒和犹太教徒大部分被的依成基督徒。

而欧洲大陆以克洛维为首的法兰克人却趁机与危机四伏的罗马帝国不断 融合。公元五世纪末期, 在充当罗马军队兵源的同时, 克洛维伺机扩大势力, 与高卢罗马人的贵族互为利用, 最终建立梅罗文佳王朝。梅罗文佳王朝及之 后的卡洛林王朝是法国和德国的雉形。

\section{2）西方大国的发展}

通过三百年的扩张, 维京文化植入环欧洲各地薄弱地带和冲突地带。“维 京文化与各地本土文化在冲突后融合而生成新的维京文化变异体一一大国原 型, 其中, 维京文化占据大国原型的社会上层, 处于引领和统治地位, 而欧 洲各地绝大多数本土居民处于顺从和被统治地位的社会下层” ${ }^{15}$ [1]。在这些 大国原型中, 不列颠原型、法兰西原型、俄罗斯原型、荷葡西原型、意大利 原型、德意志原型等已见维形。

不列颠原型的再生。维京文化移植到不列颠群岛后, 与原有本土文化经 过三百年的碰撞融合, 再生出若干维京 - 不列颠文化变异实体, 即不列颠民 族国家的原型，包括：丹麦区、北海帝国时期的英格兰王国和英格兰 - 诺曼、 苏格兰 - 诺曼、爱尔兰 - 诺曼和威尔士 - 诺曼, 奠定了不列颠的基础。

法兰西原型的再生。十世纪扩张至法兰克王国的维京人被称为诺曼人。 在维京诺曼文化冲击法兰克王国及其地缘文化过程中, 法兰西民族文化意识 逐渐觉醒并在与地缘文化博亦过程中得到强化。维京文化投入到混合着高卢、 罗马和法兰克地缘文化生态中, 经过碰撞和耦合, 再生出法兰西原型。

俄罗斯原型的再生。维京扩张时期, 东出的维京人被称为瓦良格人, 又 称罗斯人。其中一部, 由留里克三兄弟率其部族组成, “应邀” 跨过波罗的 海管理纠纷不断的斯拉夫各部落, 在内、外地缘文化关系的冲突和融合过程 中, 建立基辅罗斯并的依拜占庭基督教/东正教。后维京扩张时期, 在更广泛 的文化生态范围内, 与西方欧洲天主教世界、东方蒙古帝国、南方穆斯林世 界持续冲突和耦合, 历经数次文化断层, 陆续再生出鞑靼罗斯、莫斯科罗斯 和彼得俄罗斯, 形成了独具特征的斯拉夫 - 东正教文化形态。

维京扩张与荷兰、葡萄牙、西班牙原型的再生。公元十世纪前后, 维京 经略和劫掠前荷兰、葡萄牙和西班牙地区, 冲击了当地封建和教会统治秩序,

${ }^{14}$ (徐怀启, 122 页)。

${ }^{15}$ (汤正翔, 234 页)。 
为集中财富而实施城镇自治, 引领了商业化趋势和世俗化趋势, 为后来地缘 文化生态变动而生成三国原型奠定了商业文化基础。

维京扩张与意大利原型的再生。公元十一至十二世纪, 在欧洲各地扩张 的维京人继续以无序的方式扩张至意大利南部, 通过多次战斗和各自独立征 服, 最后建立统一的西西里王国。在其后期, 几乎建立了等同于古罗马帝国 的、环地中海的、横跨欧亚非的、包容多元文化的维京诺曼 “西西里帝国”。 维京在意大利南部扩张形成的多元文化实体奠定了十四世纪意大利文艺复兴 的基础。

多个维京变异体的缠绕制衡与德意志的再生。整个维京扩张时期, 神圣 罗马帝国阻挡了同出一源的维京武士向欧洲大陆腹地扩张, 迫使维京武士只 能沿水路在欧洲边缘地带沿海、沿江扩张。日耳曼强势推进到罗马帝国腹地, 主要路线是从北欧向南直接由陆路进入欧洲大陆腹地, 直至罗马文明的中心; 而维京扩张则主要从欧洲大陆两翼沿河海路线包抄欧洲大陆。路线的不同和 占领地域的不同，也是导致后续地缘文化向不同方向演变的重要变量。后维 京时代, 各维京变异体在维京文化商业属性引领下, 欧洲文化生态的反复分 裂、重组, 最终导致神圣罗马帝国统一梦想的破灭, 从而生成德意志民族国 家。

在以上各西方大国的原型发展过程中, 维京及维京变异体, 即各个 “蛮 族” 民族体在地域上从北向南、向西、向东渗透, 伴随罗马帝国的灭亡, 形 成了最初的西方大国原型。

\section{5. 西方大国崛起的文化再生机制}

前面已经指出, 文化是指人为了通过艺术、文学和科学来丰富自己的精 神和情趣, 所需获得的知识的总体。西方九个大国在西方文明的基础上, 分 别从物质基础、文化模式、文化生态、价值取向等方面按照既定的模式依次 崛起，从而创造了自己的文化再生机制。

在物质基础上, “维京扩张三百年, 维京人在全欧洲及其地缘范围内聚 玫财富, 奠定了强势维京文化变异体即大国原型的物质基础; 第二次维京扩 张五百年, 维京变异体即大国原型在全世界范围内聚玫财富, 则奠定了大国 原型崛起为全球大国的物质基础” ${ }^{16}[1]$ 。

在文化模式上，“大国原型在 ‘第二次维京扩张” 中复制维京文化探险 模式、劫掠模式、武士模式、贸易模式和殖民模式中的不同组合而崛起，表 现为从事包括科学研究在内的探索更广阔的未知世界、更大规模的直接掠夺、 军国主义及代理人战争、重商主义与自由贸易、殖民主义, 以及超越具体财 富而反映大国根本利益和长远利益的对国际秩序的安排” ${ }^{17}$ [1]。

在文化生态上, “维京商业文化改变欧洲文化生态和全球文化生态两个 范围的三维结构” ${ }^{18}$ [1]。宗教维度上, 维京商业文化模式从维京扩张时期的 依基督教和依附基督教会构成依附共生关系, 同时又与之缠绕制衡, 不仅争

${ }^{16}$ (汤正翔, 246 页)。

${ }^{17}$ (汤正翔, 247 页)。

${ }^{18}$ (汤正翔, 253 页)。 
夺教会权力而且为商业利益屡次突破教规大肆劫掠、基督教国家之间互相攻 伐。封建等级维度上, 维京商业文化模式以集中财富而己有为目的, 必然要 求以财富的占有量为标准划分社会层次, 即以经济等级(阶级)取代贵族等级 并以此为基础建立民族国家取代家族国家, 以资产阶级国家政权取代贵族政 权。维京商业文化通过商业革命引发的 “蝴蝶效应” 转换了欧洲文化生态和 全球文化生态中经济利益、宗教信仰和国家关系的三维结构。在此过程中, 商业革命的渐变引发的突变表现为公元十一世纪十字军东征、十七世纪欧洲 “三十年战争” 和二十世纪 “第二次三十年战争” , 即将两次世界大战作为 一个过程看待。

在价值取向上, “商业革命是维京文化弥散的必然结果” ${ }^{19}$ [1]。维京商 业文化通过维京扩张和十字军运动弥散到欧洲文化生态的基督教文化、罗马 文化及罗马文化边缘的部落文化之中。维京文化植入到基督教和王权国家依 附共生与缠绕制衡的欧洲文化生态, 与欧洲原有商业文化成分耦合, 尤以汉 莎同盟贸易范围和意大利城邦商业自治共和国最为明显。通过欧洲河流与沿 海的贸易网络, 维京商业文化嵌入欧洲各地。在维京扩张与十字军运动时期, 维京商业文化在与封建等级文化、与基督教文化依附共生和缠绕制衡的博弯 过程中, 不断得到复制, 弥散到欧洲文化生态中并再生出强势维京文化变异 体, 形成了欧洲商业革命的社会基础。以欧洲文化生态系统中正在崛起的维 京海上商业文化为基础, 商业革命于十一世纪启动, 止于十八世纪中期, 为 工业革命所取代, 确切言之, 工业革命和十九世纪的第二次工业革命以及二 十世纪的信息革命, 都是承接了维京文化启动的商业革命。最初的维京人是 指擅长海事的斯堪的纳维亚人。维京人集海盗、贸易、殖民和远距离探险于 一身, 以追逐财富、彪悍嗜血、善于海上航行为主要特征。经过从 8 世纪到 11 世纪约三百年的扩张, 显现了维京海上商业文化形态五个主要的亚文化结 构模式: 探险模式、劫掠模式、武士模式、贸易模式和殖民模式。

最后, 当今九个西方大国依次崛起的进程也是这些全球大国主导全球文 化生态 “膨胀与腐蚀” 的过程, 表现为三个维度: 第一、欧洲文明西方化、 西方文明全球化的膨胀, 相应地, 全球多元文明的 “腐蚀” 、萎缩与灭绝。 欧洲文明膨胀为西方文明辐射全球文化生态, 以至于出现当前全球文明单一 化趋势与全球文明多元化趋势之争, 且能够制衡西方文明普世化趋势的主要 力量是西方文明内部多元化趋势, 而不是非西方文明。第二、基督教在全球 传播, 相应地, 其它宗教和无神论的 “腐蚀” 、萎缩与消失。第三、全球大 国的陆续崛起, 其投射力不断增强, 大国影响力不断 “膨胀” , 非大国与弱 国的地位和实力处于边缘化、被挤压状态，因而被 “腐蚀” ${ }^{20}[1]$ 。

\section{6. 结语}

不可否认, 维京文化的五种亚文化模式的确是当今西方大国演变形成的 重要方面。但只凭这五种亚文化模式, 不足以形成西方国家特有的核心因素, 因为西方大国区别于其它大国主要在于是否接受了基督教。所以论述西方大 
国原型初始值时, 基督教是不可绕过的因素。即使在维京文化最初扩张中所 经历的五个亚文化模式中, 从武士模式开始就已经渗入了基督教元素, 之后 的贸易模式和殖民模式更是将基督教元素运用到了极致。17 世纪后, 美利坚 原型的发展更是从一开始就是清教徒文化主导的亚文化模式。这些亚文化模 式在同期的地缘文化和世界其他文化中都有不同程度的存在, 但有些却没有 演变成西方国家的模式, 足以说明这一点。

在此举一个和维京人极为相似的例子: 柏柏尔人。柏柏尔人是属尼格罗 - 欧罗巴混血人种。主要分布在摩洛哥(称里灰人、塔马齐格特人和什卢赫 人)、阿尔及利亚(称卡比尔人和沙维亚人)、利比亚(称乔夫拉人)、马里(称图 阿雷格人)等国家和地区。因此柏柏尔人在此意义上讲并不是一个单一的民 族, 它是众多在文化、政治和经济生活相似的部落族人的统称。这一点与广 义上的维京人很相似。对柏柏尔人的称呼也是来自拉丁语中的 barbari, 即 “野 蛮人” 的意思。11、12 世纪, 由柏柏尔人(Berber)建立的两大伊斯兰王朝一一 穆拉比特王朝(Almoravid)和穆瓦希德王朝(Almohad)在地中海西部一带兴 盛。“穆拉比特”一名来自阿拉伯语, 意为 “武僧”。在这个王朝的鼎盛时 期, 其势力范围包括现今的摩洛哥、西撒哈拉、毛里塔尼亚、阿尔及利亚, 南面囊括大部分的塞内加尔及马里, 北面则包括大部分的西班牙及葡萄 牙。

由柏柏尔人在地中海西部地区建立的穆拉比特王朝与穆瓦希德王朝, 常 被视作远离中东的伊斯兰世界。随着阿拉伯人不断向外扩张, 伊斯兰文明被 带到这些 “野蛮人”之中。穆拉比特王朝以及之后的穆瓦希德王朝控制了大 片土地, 也控制了这些土地上使用不同语言的定居群体和游牧群体。穆拉比 特王朝首先宣称对马格里布地区西部拥有主权, 之后跨过直布罗陀海峡到达 西班牙, 占领了安达卢斯一一西班牙南部的一大片区域。穆瓦希德王朝时期 则将领地进一步扩张至现在的突尼斯地区。12 世纪末 13 世纪初, 柏柏尔帝 国的规模达到空前水平。

因此从亚文化模式上看, 柏柏尔人发展的模式也非常类似于维京人的探 险、劫掠、武士、贸易和殖民五种亚文化模式, 但最终柏柏尔人并没有演化 成为西方大国, 其根本原因就在于柏柏尔人所信仰的宗教是伊斯兰教而非基 督教。兴于公元 7 世纪的伊斯兰教虽然继承了犹太教和基督教的思想, 也属 于一神教, “但在教义上伊斯兰教指责基督徒崇拜耶稣, 而不是敬拜独一的 上帝, 还篡改了他们的经典” ${ }^{21}$ [10]。因此基督教与伊斯兰教的分歧成了区分 西方国家与非西方国家的主要区别。除了柏柏尔人以外, 西亚的贝都因人的 历史也与维京五个亚文化模式类似, 但最终贝都因人是伊斯兰教徒的重要组 成部分。

基督教从诞生之日起就不是为某一民族或国家政体服务。犹太人曾经幻 想耶稣到来是为复苏以色列王国, 但却在耶稣生前的传道中感受到了异样, 从而最终将耶稣送上十字架。罗马帝国从最初对基督教的逼迫到将基督教定 为国教, 之后教皇的权利在很长的时间内超越了皇帝的权利, 最终罗马帝国 灭亡，但基督教的传播却超越了罗马帝国的疆域。

${ }^{21}$ (布克, 273 页)。 
因此, 从人类学层面上看, 西方大国的民族原型是源于 “化外之地” 的 不同 “蛮族” 民族, 这些 “蛮族” 民族的维京文化实体模式为其扩张提供了 最初的发展动力。但维京的亚文化模式并不是西方大国文化再生的充要条件, 因为基督教的产生、演变、发展是西方大国文化再生发展的内因。

\section{7. 本文的不足之处}

虽然本文在人类学层面上, 探索了西方大国崛起文化再生机制的两个初 始值: 基督教文化与维京亚文化。但由于跨度大、历史久远, 论述的精细度 远远不够。事实上, 自西方大国建立之后, 每个国家在各自的发展时期无不 是两个初始值耦合嬗变而成。历史上强大的西班牙帝国、大英帝国, 到至今 的美国都可以称为海洋国家, 这些国家从兴起到强大, 虽然在宗教信仰上经 历了基督教文化的不同类型, 从天主教到新教, 但本质没有改变。这些海洋 国家将维京亚文化模式运用到了极致。因此, 每个侧重点都可以从民族文化 方面展开详细论述, 尤其是对当今美利坚合众国可以更加详细地进行剖析。

本文探索西方大国崛起的文化再生机制, 但缺乏横向的比较。进入二十 一世纪, 中国经济体的数量纵比与横比均极大膨胀, 于是, “大国崛起” 与 “民族复兴” 成为中华文明集体意识。在中国经济体量显现 “高原现象” 时, 经济结构、科教兴国和创新战略在内的民族素质问题一一中华文明新内涵的 宏大命题, 赫然䇯立。在此话题上, 可以探索中西文明巨大差异的初始值。 可以探索中华文明的儒释道价值观与西方文明基督教文化的普世价值观的异 同。

最后, 本文论证时缺乏定量研究, 只是大体用历史事件推演历史进程, 缺乏史实数据。只能寄望后来者能推陈出新, 展开更精细的研究。

\section{Conflicts of Interest}

The authors declare no conflicts of interest.

\section{References}

[1] 汤正翔. 西方大国崛起的文化再生机制 [M]. 北京: 海洋出版社, 2019.

[2] Aldebert, J. History of Europe [M]. 蔡鸿滨, 桂裕芳, 译. 海口: 海南出版社, 2000.

[3] 中国基督教三自爱国运动委员会. 马太福音 $[M] / /$ 圣经. 上海: 中国基督教协会, 2007, 5: 17 .

[4] 中国基督教三自爱国运动委员会. 路加福音 $[\mathrm{M}] / /$ 圣经. 上海: 中国基督教协会, 2007, 6: 1-5.

[5] 中国基督教三自爱国运动委员会. 约翰福音 $[\mathrm{M}] / /$ 圣经. 上海: 中国基督教协会, 2007, 5: 19-26.

[6] 徐怀启. 古代基督教史[M]. 上海: 华东师范大学出版社, 1988.

[7] 包利民, 李春树. 苏格拉底“自知无知”的哲学意义[J]. 浙江学刊, 2005(5): 23.

[8] 马克.凯什岗斯基, 等. 西方文明史[M]. 第 5 版: 精编普及版. 王建平, 改编. 北 京: 中国人民大学出版社, 2015 .

[9] 吴兴勇. 古匈人进入欧洲: 人类史上第一次东西方民族的碰撞和交溶 [J]. 内蒙古 社会科学, 1992(2): 39-45.

[10] 约翰. 布克. 剑桥插图宗教史[M]. 王立新, 等, 译. 济南: 山东画报出版社, 2005. 


\section{Appendix (Abstract and Keywords in Chinese)}

\section{从人类学层面上探索西方大国崛起的文化再生机制}

摘要: 本文从人类学层面上探索西方大国崛起的文化再生机制。西方大国文 化都需以西方文明为基础, 西方文明先表现为古希腊罗马文化中的民主精神, 后有基督教传播及基督教文化深深影响, 对之后主要西方大国的崛起起到了 决定性的作用。在这个过程中, 从人类学层面上看, 维京亚文化模式, 或北 欧 “蛮族” 文化模式, 是主要西方大国发展的模式。但维京亚文化模式的探 险、劫掠、武士、贸易和殖民的各个环节中, 无不渗透着基督教文化的传播 与影响。因此, 可以说, 西方大国文化的再生机制是维京亚文化模式与基督 教文化耦合而成, 也经过了不同历史阶段的嬗变, 二者缺一不可。

关键词: 人类学, 西方大国, 文化再生机制, 维京文化模式, 基督教 